\title{
BICICLETAS, COMUNICAÇÃO SOCIAL E DEMOCRACIA NAS CIDADES \\ Entrevista a Renata Falzoni
}

\section{BICYCLES, MEDIA AND DEMOCRACY IN THE CITY Interview with Renata Falzoni}

\author{
Henrique Chaves \\ Investigador independente. Email: henrique.chaves.costa@gmail.com
}

Bruna França de Pontes

Investigadora independente. Email: bruna.frpontes@gmail.com

\section{Maria Cardoso Runkel}

Investigadora independente. Email: mrunkelcardoso@gmail.com

Resumo: Renata Falzoni tem 66 anos, é arquiteta, urbanista, documentarista, jornalista (bike e videorrepórter) e há décadas que anda de bicicleta. Não se limitando a mover-se sobre rodas, Renata é cicloativista e uma das pioneiras na valorização e defesa do uso da bicicleta como meio de transporte no Brasil. O seu documentário "O Elo Perdido - O Brasil que Pedala" foi projetado na segunda edição do Urban Audiovisual Festival ${ }^{1}$ (UAF) que decorreu entre os dias 28 e 30 de Junho de 2019 na Biblioteca de Marvila (Lisboa); na sequência desta projecção foi possível fazer esta entrevista, no dia 1 de Julho de 2019.

A bicicleta foi o fio condutor da entrevista. A partir dela, falamos de temas tais como cidade, espaço público, comunicação social, democracia, género, desportos, classes sociais; e com ela descortinamos o palco e entramos nestes bastidores. Tal só é possível devido à extensa e diversa atividade que Renata desenvolveu a partir da - e com a - bicicleta, nomeadamente a sua atividade em órgãos de comunicação social desportivos, a sua atividade política e ativista pela mobilidade urbana suave e, mais recentemente, a realização de documentários e a direção da sua plataforma online "Bike é Legal2". Esta entrevista permite, por isso, abordar um conjunto de questões caras à discussão sociológica. Ressalta-se o papel do discurso mediático na reprodução de lógicas sociais; a questão das políticas públicas em contexto urbano brasileiro; o papel das novas plataformas de comunicação online; a bicicleta como bem de consumo que pode ser entendido como acessível e democrático; e os desafios das cidades brasileiras em tempos de ataques à democracia.

A partir desta entrevista podemos fazer um exercício de reflexão sobre o viver a cidade, agregando a esta discussão novas propostas de pensar e construir um espaço urbano mais sustentável, democrático e para todos.

Palavras-chave: Brasil, género, média alternativa, mobilidade urbana.

\begin{abstract}
Renata Falzoni is a 66-year-old architect, urban planner, documentary filmmaker, journalist (bike and video reporter) and has been riding a bicycle for decades. In addition to constantly moving on two wheels, Renata is also a cycle activist and one of the pioneers in the valorization and defense of the use of the bicycle as a means of transport in Brazil. Her documentary "O Elo Perdido - O Brasil que Pedala" was screened in the second edition of the Urban Audiovisual Festival (UAF), which took place between the $28^{\text {th }}$ and $30^{\text {th }}$ of June 2019 at Biblioteca de Marvila (public library in Lisbon). This interview took place on the $1^{\text {st }}$ of July 2019 as a follow up to the screening.
\end{abstract}


The bicycle was the guiding thread for the interview. It allowed us to talk about the city, public spaces, the media, democracy, gender, sports and social class, accessing the "backstage", and unveiling different possible discussions. This was only possible due to the extensive and diverse activity that Renata developed from - and with - the bicycle. Namely, her activity in sports media, her activism and political activity towards smooth urban mobility. Recently, she has directed her efforts into documentary film-making and to the direction of her online platform "Bike é Legal". This interview addresses a set of issues that are important for the sociological debate. Among these are the role of the media in the reproduction of certain social logics, the issue of public policies in the Brazilian urban context, the role of online communication platforms, the bicycle as a consumption product which can be understood as accessible and democratic, and the current challenges for Brazilian cities when faced with attacks on democracy.

This interview enabled us to reflect on how to live the city, adding new proposals to think and build more sustainable and democratic urban spaces for all.

Keywords: urban mobility, Brazil, gender, alternative media.

\section{A Renata é descrita na comunicação social, em vários portais e redes sociais como pioneira no uso e divulgação de bicicleta no Brasil. Conte-nos um pouco deste trabalho que começou em meados dos anos 70, chegou até hoje e projeta-se para o futuro.}

Na década de 1970, estava a estudar Arquitetura na faculdade e nesta altura praticamente fugi de casa. Fui morar numa casa na Vila Madalena (bairro do município de São Paulo), que era mais perto da minha faculdade. Eu já pedalava, mas não como meio de transporte de forma intensa. Em 1976, dei o meu carro de presente para o meu irmão, comecei só a andar de bicicleta e terminei o curso de Arquitetura pouco depois, em 1977. Como estudante de arquitetura, muito da boémia, rodando na noite e madrugada, rapidamente percebi que a cidade não era desenhada nem para pedestre - se eu queria passar uma ponte, se eu queria chegar a algum lugar, nem fingindo ser pedestre conseguia. E eu comecei a questionar muito isto. Quando as pessoas falam que sou a mais importante, na verdade talvez eu não seja a mais importante, mas pela minha resiliência e por tanto tempo que eu estou me mostrando de bicicleta e eventualmente trabalhando mais, trabalhando menos, mas sempre sendo vista de bicicleta.

Isto começou forte a partir do ano de 1976 e, nos anos 1980, teve uma outra pegada. Porque em 1984 eu entro no grande jornalismo. Comecei a trabalhar em jornalismo, apesar de ser arquiteta, e comecei a trabalhar na fotografia. Entre 1978 e 1979 já vivia de fotografia e entre 1981 e 1982, comecei a entrar na grande imprensa, nos jornais e grandes revistas. E todas as vezes que eu tinha alguma oportunidade a pauta era a "bicicleta", ou na forma do lazer, ou competitiva, ou ainda como meio de transporte além do carro. Há quem fale da bicicleta como "alternativa", palavra 
de que não gosto, eu acho que o alternativo é o carro, nós somos os orgânicos. E no ano de 1988 foi quando eu comecei a fotografar profissionalmente com um nível diferente para grandes empresas e publicidade, ganhava mais dinheiro com menos tempo de trabalho. Então comecei a investir um tempo não útil na mobilidade, na proposta de coisas mais sérias em relação a se mover de bicicleta. Foi quando criei o Night Biker's Club, um clube que começou a convidar a classe média e a classe média alta a pedalar com bicicletas que agora estavam chegando ao país, que já não eram umas bicicletas entendidas como de trabalhador. Era uma bicicleta com muito valor agregado. O objetivo era pedalar à noite na cidade, para usufruir da cidade de forma ativa, e estas mesmas pessoas que naquela época vinham de carro hoje em dia já se transportam de bicicleta na cidade. Nesta altura negociávamos fervorosamente soluções para bicicletas nas cidades, até então a bicicleta não era incluída no Código de Trânsito Brasileiro. Toda a vez que ela aparecia, era para ser proibida. A bicicleta só passou a ser vista como legal, como direito e como meio de transporte, a partir de 1997, num código de trânsito que entrou em vigor em 1998. No país ainda precisaríamos de 10 anos, mas em 1990 conseguimos passar leis muito importantes na cidade de São Paulo, por exemplo que todas as novas avenidas, viadutos e outras reformas urbanas deveriam ter estruturas cicloviárias. Nunca se cumpriram estas leis, temos um défice muito antigo. As leis que foram entregues naquela época teriam feito uma revolução pela cidade. Nós éramos ativos, mas éramos sistematicamente não reconhecidos como de legítimo direito, muito apesar das leis que se promulgava. O Brasil tem esta coisa de lei que pega e lei que não pega, e as nossas leis são as que não pegam, são as leis que não satisfazem aos "carrocratas", as pessoas que estão em cima de um poder que não podem perder em função de leis. Estas leis são sistematicamente desobedecidas.

A coisa tomou uma outra figura em 1995, quando entrei para a televisão. Comecei um jornal de ciclismo muito forte, estava nesta questão da comunicação e da pressão por políticas públicas. Políticas públicas estas que, repito, não eram executadas porque as leis eram sumariamente negadas. Mas em 1997, a partir da discussão do novo Código de Trânsito Brasileiro, participei numa campanha muito grande que foi pedalar de Paraty até Brasília, foram mil e seiscentos quilómetros. Começamos no município de Paraty, no estado do Rio de Janeiro, e cruzamos este estado e os estados de São Paulo, Minas Gerais, Goiás, e entramos no Distrito Federal no dia da entrada em vigor do novo Código de Trânsito, exigindo que o Presidente Fernando Henrique Cardoso ${ }^{3}$ trabalhasse no sentido de cumprir este código. Eu até fiz um filme a este respeito que está no nosso canal de YouTube, chama-se "Bicicleta Brasil - Pedalar é um direito"4 (2018). Este foi praticamente o último trabalho que fiz nesta fase de militância mediática, como eu falo, de cerrar a 
comunicação social e fazer a imprensa cobrir o que se está a reivindicar. Depois disso nós ainda fizemos ação, uma muito importante com o prefeito Celso Pitta ${ }^{5} \mathrm{em}$ São Paulo. No ano de 1996 ainda tentei ser candidata para vereadora para a cidade de São Paulo. E não fui eleita, mas coloquei na pauta da campanha política estas questões.

Ainda nesta altura, no ano de 1999, eu entrei muito séria no trabalho da ESPN (canal televisivo de grelha desportiva), comecei a produzir matérias para televisão. Como a produção recaía em cima do meu budget, fiz um contrato com a TV em que eles me davam o dinheiro e eu fazia o que entendesse com ele. Eu cobria o desporto de alto rendimento, basicamente, bicicleta, ciclismo, mountain bike, ciclismo de estrada, $\mathrm{BMX}^{6}$, e cobrindo também as pistas de BMX feitas por crianças nas periferias colocando isto no mainstream como práticas de cidadania. Trabalhando todo um advocacy da comunicação da bicicleta, e isto só surgiu nesta época. Nesta altura foi muito importante a entrada da internet no circuito, as redes sociais, as salas de discussão. Até então eu estava usando fortemente a televisão como principal meio de comunicação, ainda que produzisse filmes e documentários. Paralelamente, o pessoal se estava organizando sobretudo no início da internet e eu, sem saber, inspirando-os. Este reconhecimento vem de uma inspiração, não tanto de uma proatividade minha, mas de uma inspiração de eu estar pautando o assunto. E continuo nisso.

Começamos a ter o "Dia Mundial Sem Carros", cada vez com uma massa maior de pessoas a participar. E nas atividades deste dia do ano de 2007 aconteceu uma coisa muito bonita na minha vida. Eu fico até emocionada, porque foi um dia que eu percebi que eu já podia morrer, porque já não precisavam mais de mim! Aliás, já não precisam mais de mim. Isto é muito legal, porque já não está mais comigo, aquele fardo de ter que estar em toda a reunião, de ter que estar provocando, de ter que se desdobrar, de ter que deixar filho de lado. Não, agora não precisam mais de mim. Claro que você está lá, você está presente quando a coisa está delicada, você vai lá, puxa a câmara, bota um microfone na cara das pessoas, dá voz para quem está falando, gravar a voz de quem está prometendo e não está cumprindo. A partir desta época começou, com muita intensidade, a formalização dos cicloativistas. E 2009 também foi um ano muito importante, que foi quando surgiu a Associação de Ciclistas Urbanos de São Paulo (Ciclocidades7) na cidade de São Paulo e também o Instituto CicloBR de Fomento à Mobilidade Sustentável (CicloBR ${ }^{8}$ ). Estas organizações são verticais, com Cadastro Nacional da Pessoa Jurídica (CNPJ), com eleição, com uma coisa não horizontal, horizontal você está de máscara jogando pedras, lá você tira a máscara, você senta e troca um cartão e negoceia. Amadureceu muito rápido o cicloativismo lá em São Paulo e eu fico muito feliz de ter um cargo não eletivo, mas de observadora. E toda a vez que têm conflitos eles me chamam e 
falam “você não precisa falar nada. Só em estar lá, a turma se apazigua". Eu fico muito feliz porque é assim, eu sou muito de "eu brigo, mas não com os nossos. Com os nossos eu busco muito somar com as nossas diferenças". E às vezes precisamos trazer esta necessidade de somar.

Eu vejo muitos vídeos seus para aprender dicas sobre bicicleta, e são recursos educativos muito importantes. São importantes para os ciclistas pensarem como é que andam numa cidade, como é que pensam a cidade, e também como olham para a bicicleta. Com isto, começamos a ter uma relação com a bicicleta de maior autonomia, porque não precisamos de nos preocupar com outras pessoas, nomeadamente para consertar a bicicleta. Conseguimos fazer isso com a ajuda do Youtube e dos seus vídeos. Já fez algumas introduções sobre esta questão. Queria que falasse um pouco sobre isso, sobre o impacto do seu trabalho com audiovisual no YouTube nos últimos anos, que chegou a todo o Brasil e a Portugal. Está a fazer muito sucesso e é sobre bicicleta, sobre como andar, como pensar, um pouco de tudo.

Quando eu comecei a pedalar e a descobrir uma cidade nova, era uma cidade de um país que uma mulher não podia trabalhar depois das seis da tarde, a mulher não podia viajar sem autorização do marido, era um espaço em que a mulher não podia ir para a rua. Quando eu comecei a pedalar como meio de transporte, era uma coisa muito interessante porque as pessoas viam uma pessoa numa bicicleta, não era um homem ou mulher, era um "it", até o pessoal entender que era uma mulher pedalando e eventualmente mexer ou soltar um texto de violência, eu já tinha passado. Por isto, muito rapidamente eu comecei a proteger-me na bicicleta e ter uma carga de amor muito grande em relação a isto. Sabe quando você se explode de amor, de estar gostando e adorando aquela aventura de andar na cidade, descobrir novos caminhos, descobrir novas trilhas, novos lugares maravilhosos?... E você rapidamente quer passar isto para os outros. Toda a minha carreira vem desta vontade de que os outros também vivenciem aquilo que eu estou a vivenciar.

Quando eu fui para a faculdade de Arquitetura, entendi que aquela Arquitetura que eu estava aprendendo não era a profissão que eu queria exercer. Eu queria estar na rua e comecei a fotografar e pedalar muito. Assim que saí da faculdade, entrei para o jornalismo. E procurei ser uma jornalista contadora de histórias e com toda aquela munição de querer que as pessoas façam aquilo de que eu gosto. Embora eu trabalhasse como fotógrafa num grande jornal, rapidamente consegui uma vaga para escrever e fotografar no turismo. E criei uma sessão nova de turismo de aventura. Nesta época eu até nem pedalava tanto. Pedalava como meio de 
transporte, mas não havia a mountain bike ainda. Era 1984/85, eu ia para as trilhas com bicicletas, mas eu fazia matéria de mergulho, de escalada, matéria de caminhada. Sempre propondo através da minha vivência "venha você também, se eu faço, você também faz". Porque eu não faço coisas arriscadas. Eu faço coisas sempre na pegada que eu não sou melhor que ninguém. Porque se eu faço, você faz. E eu sempre terminava as matérias que fazia na televisão com: "está aqui na sua telinha o link do site para você também vir fazer o que eu estou fazendo". Apesar de eu ter uma profissão que cobria o alto rendimento, quando eu pautava, cobria sempre aquilo que é possível para todos, para famílias e especialmente para as mulheres. Mas sem distinção, "isto aqui é de mulher e isto aqui é de homem” não, não, não! Aqui você não precisa força, você tem que ter só inteligência e agilidade.

Eu demorei muito para conseguir entrar na televisão, isto foi um projeto de vida como também fazer aquilo que chamamos de videorreportagem, que é fazer matérias com uma pessoa só, com equipamentos leves, compactos. Não é que eu não quisesse ir com mais alguém, era por uma questão de custo. Porque quando eu consegui finalmente entrar na televisão, a mim cabia só os desportos que eles não queriam. Que não era o futebol, era os desportos que não davam medalhas para o Brasil, que eles não conseguem cobrir e que eram os desportos que cansam muito para você subir a montanha para falar com as pessoas. Com isso, criei um departamento dentro da TV, que era a videorreportagem, e nisso eu sou bem precursora no Brasil, que é trabalhar com essa linguagem de uma câmara só. Eu vinha de fotografia publicitária e já tinha uma noção muito forte de fotografia de cinema, já fazia rádio, já tinha tido um jornal próprio; por tudo isto eu dominava muito o texto, a foto e falar na média. Portanto, quando comecei a fazer videorreportagem foi só uma soma destas coisas e ter agilidade da edição para criar conteúdo para a TV, onde é tudo muito pequenino, muito curto, tem que ser muito ágil para não perder a audiência.

Assim, eu sou a única que filma ciclismo de alto rendimento, sou a única que filma prova feminina, os homens ficam com a prova masculina. Quando estava na televisão e ia editar o material gravado nas provas femininas de ciclismo, percebia um problema. Eu via que o empenho que as mulheres tinham, pelo menos no Brasil, era diferente do empenho masculino. Não eram tão competitivas durante grande parte da prova, via-se que estavam sempre a neutralizar para resolver a prova nos últimos 300 metros. Eu chegava para elas e falava que estava na televisão a tentar colocar a prova, mas o que eu filmo de vocês é neutralidade, e elas diziam-me "é o meu técnico que não quer que eu faça fuga", e eu respondia-lhes que enquanto não tiverem competições com luta, eu não vou conseguir batalhar junto dos meus editores, que são homens, e que estão em cima da audiência e da adrenalina. Com 
provas assim, não tenho condições de ficar batalhando, "preciso que vocês deem sangue, e eu dou sangue também e aí vão ter um bom espaço". E agora a mulherada no Brasil está-se mostrando, dá uma olhada no World Cup Feminino, estão com sangue nos olhos, isto é legal, porque consigo brigar para que os homens vejam. Não é só dizer que não há espaço, é preciso a mulherada "dar sangue".

Quando a ESPN acabou com o departamento de desporto para além do futebol, eu criei o Bike é Legal, que é uma rede que está num canal de YouTube e está sempre a dar dicas, como comentaste. A partir do momento em que temos o nosso próprio canal, só fazemos o que bem entendemos. Nós começamos a trabalhar em cima daquilo que eu não conseguia fazer na televisão, que é ensinar o básico e bater muito na mesma tecla, pois eu não acredito que a bicicleta seja complicada, ela é muito simples. Para demonstrar isto, no início do canal, destrinçava uma bicicleta para explicar e demonstrar quão fácil era fazer aquilo que eu estava a fazer. E ainda assim havia uns comentários bem machistas do tipo "o que é que essa velha entende" e eu pensava "eu não entendo nada, eu só fiz cálculo num estrutural de vigas e eu não entendo nada". Eu me lembro de ter feito uma matéria há dois anos atrás com um grande amigo que trabalha comigo. E pedi-lhe para fazer o teste de uma mountain bike de carbono, enquanto eu gravava ele falava da bicicleta. E ele perguntou-me "Renata, o que falo sobre esta bike?", e eu respondo-lhe "desta bike, fala isso, isso e aquilo..." e ele falou "esta bike, isso, isso e aquilo...". E veja, os comentários sobre este vídeo eram "este cara é que entende!" (risos). Ele deu a minha pegada e é "este cara é que entende e a outra não entende nada". Então, eu pensei "estamos, de alguma forma, no caminho certo". Atualmente, eu procuro aprofundar com muita simplicidade as coisas mais difíceis e evitar o "falar difícil". E o nosso grande desafio é trazer mais mulheres para o canal. Que por mais que seja eu, uma mulher, por mais que eu descomplique, a mulherada não está lá. Poucas com mais de 50 anos, a maior faixa é entre 16 e 35 anos. No total, são só $12 \%$, já foram $9 \%$, estamos crescendo.

Passando agora para outro assunto, aqui em Portugal, na Escola Secundária da Gafanha da Nazaré cerca de 300 a 400 dos estudantes vão para escola de bicicleta, perto da metade do total de estudantes desta escola.

Onde fica?

No município de Ílhavo, perto de Aveiro.

E sempre foi assim? 
Já faz algum tempo, porque passou de pais para filhos. Por exemplo, as mães andavam de bicicleta para trabalhar...

Eu vou voltar cá para ir filmar isso.

Eu estive lá, há pouco tempo, com o propósito de conhecer a escola e os projetos que estão a ser desenvolvidos sobre bicicletas. E é interessante ver que a garagem da escola é imensamente ocupada por bicicletas e poucas com cadeados a prendê-las.

E não está diminuindo?

Não, não está. Este fenómeno português é pouco conhecido, eu soube por causa de uma reportagem na impresa portuguesa ${ }^{9}$. Estas cidades não são valorizadas. O que é valorizado é o que acontece nos grandes centros urbanos.

Pegando nisto, faço uma pergunta; no seu filme “Elo Perdido - O Brasil que Pedala ${ }^{10 "}$ é abordada a questão da entrada de bicicletas na agenda política das cidades nos últimos anos. Em Lisboa, há pouco menos de dez anos atrás, praticamente não existiam estruturas, a bicicleta era quase invisível no espaço lisboeta. Em poucos anos houve muito investimento aqui em Lisboa, criaram-se as Giras, as bicicletas partilhadas do município, e muitas ciclovias. No Brasil aconteceu a mesma coisa nas grandes cidades. Porém, nos exemplos que apresentou no filme, a bicicleta é uma constante. Nomeadamente, Afuá (município do estado do Pará), onde praticamente toda a população do município anda de bicicleta e o carro motorizado está proibido, ou na balsa de Santos (município do estado de São Paulo) em que vemos uma balsa (ferryboat) a chegar ao seu porto e a maioria das pessoas ali estão com a sua bicicleta para seguirem para o trabalho.

Gostava que comentasse essa questão. Há cidades que criam condições e infraestruturas para andar de bicicleta, e se popularizam por isto, mas há outras cidades onde já se andava de bicicleta há um tempo atrás e não eram tão famosas por isso.

Qual a sua percepção sobre estes contextos?

Quero mesmo conhecer essa cidade.

Então, eu idealizei esse filme, o "Elo Perdido", há mais de 14 anos atrás. Eu sabia da cidade de Afuá, e previa ir para uma série de outras cidades, no norte e nordeste do Brasil. Por fim quando eu tinha dinheiro para fazer, liguei para o meu amigo lá de Teresina (Piauí), e ele disse, "Renata, nem vem para cá. Tudo aquilo que você viu acabou." Nessa pré-produção do filme, eu procurei locais onde as bicicletas não estavam diminuindo. 
O caso da balsa de Santos está relacionado com uma lei que foi aprovada no Estado de São Paulo, esta lei diz que todas as estradas teriam que ter ciclovias e o ciclista não precisaria de pagar pedágio (portagem) em travessias como as das balsas. Os ciclistas que usam esta balsa pedalam uns oito quilómetros por dia, casa-trabalho. Para o trabalhador paulistano é caro pagar 80 centavos por dia para ir trabalhar, aquela balsa persiste porque eles obedecem à lei e não cobram e também devido à questão de ser mais rápido ir para o trabalho de bicicleta e balsa do que de ónibus (autocarro).

O filme abre mostrando o que aconteceu com o Brasil. A bicicleta era um bem de consumo, muito valorizada e acessível a todos. Nos censos brasileiros existia uma ausência de perguntas relacionadas com a quantidade de bicicletas que as famílias tinham em casa. Perguntava quantos rádios, carros, banheiros as famílias tinham, mas não perguntava quantas bicicletas. E eu acho que isso é totalmente intencional, pois promove uma indústria - o motorizado. A bicicleta está totalmente associada a um não desejo da política pública, porque na cabeça deles, não está a promover a economia. Eu tenho até um apontamento para dizer sobre isso, que é o motivo do porquê eu me desfiliei do Partido dos Trabalhadores (PT). Quando lá estava, diziam me "todo o mundo a morrer de fome e você só fala de bicicleta, nós do PT queremos luxo para todos e carro para todo o mundo". Isso em 1984/5, eu falei "até logo, a esse partido eu não pertenço". O Lula fez crédito para carro, em vez de criar transporte público. Ele é brilhante, mas nesse caso...

\section{É continuidade daquilo que já se fazia nos anos 50/60, que foi inativar a ferrovia e construir estradas no país todo. Há um défice gigante de ferrovia por causa disso.}

Pois é, isto é uma continuidade de política direcionada aos carros. Mas também pouco pensada para intermodalidade. No filme, aborda-se a questão do estacionamento de bicicletas a partir de um conflito que houve numa estação ferroviária de Mauá (município de São Paulo). As pessoas colocavam as bicicletas amarradas às grades da estação, junto das casas, por todo o lado e isso causava transtorno e atrapalhava a fluidez dos passageiros. A Companhia Paulista de Trens Metropolitanos (CPTM) procurou dar resposta a este problema atribuindo a um dos seus funcionários a tarefa de proibir o estacionamento das bicicletas naquelas condições; em vez de simplesmente proibir, este funcionário deu resposta ao problema fundando o Ascobike ${ }^{11}$, um espaço de estacionamento de bicicletas - bicicletário. Este bicicletário recebe mais de mil e duzentas bicicletas todos os dias.

Voltando para São Paulo, temos uma gestão estadual e a Prefeitura unificada na ideia que as ciclovias são para ser faladas, discutidas, mas não implementadas e 
muito menos com manutenção regular. Só que, por conta das bicicletas compartilhadas, por conta de um desejo da população, houve um aumento enorme no uso da bicicleta. As ciclovias que pela lei deveriam ter sido realizadas em 1996 - por causa da lei de 1990, que mencionei anteriormente - só foram realizadas em 2013. Apesar de ter sido uma ciclovia que demorou muito tempo para ser realizada, ela já está saturada. Ao ponto de ter entre 8 mil e 10 mil ciclistas por dia.

Ainda no filme, quando falamos do Rio de Janeiro, vê-se a questão dos trabalhadores. Com as infraestruturas cicloviárias, que foram das primeiras do Brasil, ao longo da orla, toda aquela logística de distribuição é feita por triciclos, e por gente que não tem carro, e também há crianças pedalando, a cidade do Rio de Janeiro nunca deixou de pedalar!

Sobre Afuá, é uma cidade em que todas as matérias que eu conheço focam numa coisa que eu nem mostrei no filme. Está lá no visual, mas eu nem falo - é o bicitáxi, uma bicicleta dupla, com quatro rodas que se assemelha a um carrinho. Aquilo é o objeto de desejo de todas as matérias sobre Afuá, a réplica do carro. E ignoramos isto, porque o bicitáxi é responsável por menos de $1 \%$ das viagens da cidade. A bicilância, ambulância em bicicletas, é feita a partir daquilo. Lá os bombeiros têm um carrinho de apagar incêndio movido a bicicleta. A população chegou a ter motos lá, mas depois de dois meses o Prefeito entendeu que as motos iriam destruir as palafitas feitas de madeira e também por causa dos riscos de acidentes. Assim foi proibido, e a população apoiou. Tanto é que eu fui ver a lei de lá, a lei não fala de motor, fala de matriz energética e peso. Tanto que uma bicicleta elétrica, segundo aquela lei, poderia entrar naquele município, mas eu não expliquei muito isso no filme, que é para as pessoas não terem ideias. Afuá é lugar que funciona de forma completamente orgânica, não tem uma placa de sinalização, não tem nada, é algo que nem em Amsterdão conseguimos ver.

Então é assim, o filme busca lugares onde ainda existe a bicicleta. Agora nós temos cidades, como por exemplo Cáceres (Mato Grosso), que tinham $80 \%$ das viagens sendo feitas em bicicletas, hoje caiu para $17 \%$. É uma cidade em que a motorização está estragando de tal maneira, que eu não fui lá mostrar. Eu não busquei nenhum lugar em que a bicicleta está perdendo. E foi de propósito!

Agora o Brasil fabrica quase dois milhões de bicicletas por ano. Nós temos um parque fabril enorme. Onde estão estas bicicletas? E o mais interessante, que com a gentrificação da bicicleta, que você vê na cidade de São Paulo, onde tem gente gastando 10 mil reais numa bicicleta e gente com bicicletas de 300 reais... Quanto deve dar em euro?

\section{Atualmente, uns 80 euros...}


Entre 80 e 2 mil euros. Tem de tudo lá! Agora, o que é interessante é que a indústria não consegue mais fornecer a bicicleta de 80 euros, as bicicletas do trabalhador brasileiro, isto devido à taxação. Estas bicicletas são montadas em oficina fundo de quintal, por exemplo, lá na cidade da Afuá, as bicicletarias vendem 30 a 40 bicicletas por mês. Coisa que para uma cidade de São Paulo é um bom negócio. Devido a estas informalidades, não temos uma estimativa correta de quantas bicicletas montadas em bicicletarias são feitas no país, e por mais que a indústria formal critique isso, a indústria formal não quer esse negócio, porque são muitos clientes, com baixo valor agregado e muita manutenção para fazer. Então eles preferem vender menos bicicletas, mas com maior valor agregado. Mas este mercado mais informal pode ser muito representativo, eu acho que deve ser mais do que $50 \%$ do mercado formal. Ele é abastecido por quadros feitos no Brasil, montados em oficina de fundo de quintal. Conseguimos ter uma ideia da dimensão desse mercado por conta do número de pneus que são vendidos no mercado brasileiro, só por isso.

Falando disso ainda: durante a UAF falou que era preciso "Afuanizar as cidades" e não "Copenharizar", pode explicar essa ideia? Tendo em conta, por exemplo, que aqui em Lisboa, nos próximos anos, se pretende duplicar o tamanho das ciclovias que existem na cidade, atualmente existem $100 \mathrm{~km}$, propõe-se chegar aos $200 \mathrm{~km}$ até 2021.

Vai ser muito difícil internacionalizar o termo "Afuanizar", não é? (Risos) Então, vou explicar bem a diferença.

Afuá é uma das cidades que tem um dos piores Índices de Desenvolvimento Humano (IDH). É uma cidade em que o rendimento per capita é muito baixo, mas ao mesmo tempo é uma cidade que tem índices de violência muito baixos. Então é uma cidade em que é muito mais identificável a realidade de "Terceiro Mundo". Você vai para Copenhaga e o IDH deve ser dos melhores do mundo, com rendimento médio relativamente alto. Mas em nenhum lugar no mundo em que eu já pedalei, como Copenhaga ou Amesterdão, nestes lugares eu nunca vi uma criança de 7 anos pedalando e levando uma outra para a escola na mesma bicicleta. O acesso de uma criança à cidade se dá pela total ausência de velocidade nos caminhos. Eles são olho no olho e velocidade orgânica. Isso é muito interessante, quando lá, em Amesterdão, quase ia criando acidente por não dominar isto completamente.

E tem mais, eu não sei quais são os índices em Copenhaga, com certeza que são altos - em Amesterdão são altos. Em Afuá, o índice de mulheres que pedala é de 52,54\%. Afuá consegue pela simplicidade, pela baixa velocidade de toda aquela cidade, ser uma cidade realmente acessível às crianças, adultos, velhos e pedestres. 
Isto não é uma questão de ciclovia, é uma questão de que o espaço onde as pessoas vão a pé, outras vão de bicicleta, e até os cachorros não têm problemas naquela cidade. Então é assim: eu vejo que o conceito de Afuá é muito superior a qualquer um de Copenhaga pela raiz, simplicidade, organização e descomplicação. Tanto que eu projetei o filme Afuá e me sentia até envergonhada porque nada daquilo que eu estava mostrando era novidade para eles. Agora o que era novidade é que eles eram tão interessantes e importantes. Aquilo tocou-lhes - "Poxa vida, nós somos interessantes porque somos o que somos". No fim da projeção do filme com eles eu me senti aliviada, pensei "tem sentido em projetar esse filme aqui". Era uma novidade mostrar-lhes que não havia lugar no mundo onde uma criança de 7 anos levava uma de 3 anos na mesma bicicleta e nenhuma mãe estava desesperada. Isto não acontece em Amesterdão ou em Copenhaga, não dá para você soltar uma criança de 3 anos numa cidade como Copenhaga, porque lá existe carro.

Passava agora às questões mais relacionadas com a democracia. No seu documentário, Afuá é apresentada como um lugar muito democrático, a bicicleta é um meio democrático, é um meio de acesso fácil para todos, é barato e acessível. O documentário propõe essa questão de classes - da bicicleta ser acessível para todos. E como já se falou anteriormente, também acessível independentemente de género e etnia. E sei que é uma defensora da necessidade de incluir estas questões no discurso sobre bicicletas, como também dá importância a incluir a questão das pessoas com mobilidade reduzida, porque não são só homens que andam de bicicleta. No seu canal de YouTube, como já falou, há uma percentagem baixa de mulheres que acompanham e gostaria de chegar a mais mulheres. Como é que estas pessoas podem ocupar e usar a bicicleta na cidade? As mulheres e pessoas de outras origens? As pessoas imigrantes e refugiadas? Gostaria que apresentasse um pouco o que pensa sobre estas questões e a sua reflexão sobre a relação entre bicicleta e democracia.

A bicicleta ela é tão gentil, não é? Sobre as pessoas refugiadas, o Brasil está recebendo uma onda muito grande da Venezuela. Tive a oportunidade de fazer um filme curto, de sete minutos, sobre uma oficina que o Aromeiazero, que é uma entidade lá de São Paulo, está fazendo com refugiados venezuelanos para ensiná-los a trabalhar com bicicleta, dando-lhes possibilidade de trabalhar como empreendedores a partir da bicicleta no Brasil. O que me incomodou naquele documentário é ver quem eram aquelas pessoas. Eles eram pós-graduados, professores, pessoas com formação muito maior que a minha, em termos de estudos, e estão lá a trabalhar para serem mecânicos de bicicletas para começarem a ter outra vida. Como é que os 
refugiados estão a chegar ao Brasil, como é que eles podem locomover, como é que eles podem começar a trabalhar, sabendo que tudo é tão caro? É uma opção de quem não tem opção, começa pela bicicleta. Não é só para ir à procura de trabalho, mas eventualmente para trabalhar naquilo. Existem muitas oportunidades como mecânicos em oficinas mecânicas em São Paulo. Uma outra oportunidade muito grande que está acontecendo com bicicleta, e não estamos conseguindo impedir a sua precariedade, é esse fenômeno que são os entregadores por aplicativo. Então imagina a cidade de São Paulo com 17 milhões de habitantes e as pessoas vêm de 30 a $40 \mathrm{~km}$ da periferia para o centro para trabalhar. Não é que o transporte público seja ruim, mas nenhum transporte público no mundo consegue trazer 5 milhões de passageiros de manhã e devolver 5 milhões de passageiros à tarde sem ser um caos, é o que faz São Paulo todo dia - por isso é caro e é ruim.

\section{(risos) Isso é metade de Portugal, que tem 10 milhões de habitantes. Metade de Portugal vem para cá e metade vai para lá.}

Muitas destas pessoas são jovens que estão vindo de uma periferia muito longe e de uma realidade muito precária. E conhecemos muito bem a oferta de trabalho que encontram mais facilmente: é fazer aviãozinho (entrega) para traficante. Um rapaz de periferia hoje tem mais chance de pedalar do que um do centro da cidade, melhor posicionado. Os de classe mais alta não conseguem pedalar e os de periferia conseguem porque têm acesso à bicicleta mais facilmente. Vêm todos os dias da periferia para o centro para trabalhar em empresas de entrega por aplicativos e serem mini empreendedores super precarizados. Quero muito fazer um filme sobre isso, sobre essa realidade, sobre o que isso está impactando na família destas pessoas, num país que está com 12 milhões de desempregados. Eles têm 18 anos e nenhuma perspectiva de emprego. As pessoas criticam-nos porque ficam empinando ${ }^{12}$ a bicicleta, mas eu fico aplaudindo. Primeiro porque eu não sei empinar, segundo porque eles estão mostrando, com evidência, o quanto precisam de seus serviços reconhecidos, e o quanto são hábeis e o gostam da bicicleta. Por outro lado, a circulação de bicicleta entre a periferia e o centro é um caos e um horror, as pessoas são atropeladas na rua, ninguém pára, ninguém respeita. Em suma, a realidade destes jovens é essa: precarizadíssima.

Um outro impacto muito grande que está a acontecer é o surgimento dessa bicicleta gentrificada, que está acontecendo em São Paulo. No take de fechamento do filme "Elo Perdido" o foco está nos pés de várias pessoas que estão a pedalar, e vê-se uma pessoa pedalando com melissinha, outra com galocha de açougueiro, e sapato de couro que custa caro, e ténis - isto é uma grande inclusão social. As 
pessoas desta classe social que se prendia no carro, a segregação era sinónimo de segurança para eles, agora eles estão entendendo que isto não faz sentido. O que faz sentido é aceitação, é o convívio, é o compartilhamento, é estar junto. Eles não gostam de ver estes jovens empinando a bicicleta, mas estão dividindo espaço público com eles. Sabe quando eles iam dividir algum espaço? Se fosse na calçada, nunca. Se fosse no trem/ônibus/metro, nunca. E eles estão pedalando lado a lado. Ouvindo a gíria deles. Por exemplo, quando estão parados no sinal, imagina que estes jovens da periferia perguntam "esse teu freio é a disco? é a disco mecânico?"13. Os de classe média/alta ficam logo apavorados, porque acham que vão ser roubados. Mas se eles começarem a conversar, pode-se criar uma grande amizade ali. Entendeu? Isto está provocando nessa classe média/alta brasileira, que é muito segregada, fechada na bolha e que tem medo do espaço aberto, um entendimento do valor do espaço público e da sua ocupação.

Esta minha última questão está relacionada com aquilo que acabou de falar. É uma questão sobre o Brasil atual. Qual é, na sua opinião, o peso das políticas de governos como o de Bolsonaro para as cidades e o uso da bicicleta? Em vários dos seus discursos, o atual governo brasileiro valoriza o carro, e tudo o que está relacionado a ele. Qual é o impacto nas cidades brasileiras?

A pergunta é bem complexa, porque eu tenho um certo receio de associar a promoção da mobilidade da bicicleta a uma pegada da esquerda e a promoção da mobilidade de carro a uma pegada da direita, muito embora no atual cenário da cidade de São Paulo possa ser entendido dessa forma. Porque essa confusão é muito perigosa, em todos os sentidos. Primeiro, porque ocupação do espaço público, você transportar e fazer as cidades mais humanas, tem que ser política de governo independente da tendência. Você não pode deixar de promover saúde pública, que as pessoas escovem os seus dentes todos os dias, tomem os seus banhos, tudo, porque você é de direita ou esquerda. E eu vejo da mesma maneira a promoção do espaço seguro a todos. Porque quando se fala em mobilidade da bicicleta ou mobilidade das pessoas, nós estamos desenhando cidades que tenham uma menor taxa de morte de pessoas nas ruas por acidentes automobilísticos. Isto é perigoso. Mas respondendo à tua pergunta, vou dar um exemplo. Quando João Dória ${ }^{14}$ era prefeito, criou um slogan chamado "acelera, São Paulo", e acelera com um "V" deitado ${ }^{15}$. Isto era um contraponto a Fernando Haddad ${ }^{16}$, que é do PT e tirou a cidade de um vácuo, um atraso muito grande das políticas públicas voltadas para as pessoas da cidade. Haddad executou ciclovias que estavam desenhadas há 20 anos, tirou do papel uma coisa que já estava negociada e acertada, e que estava sempre a não ser 
respeitada. Dória, com esse "acelera", de fato aumentou as velocidades na marginal, e também aumentou consideravelmente as mortes de pedestres e ciclistas nesses últimos 3 anos na cidade. E ainda dizem "mas nem aumentamos a velocidade nas ruas!", como sabemos ele mandou a população "acelerar". E a população tornou-se não calma, mais agressiva, e já associando que todo ciclista era de esquerda, já ia atropelando. $O$ atual presidente já anunciou que não vai renovar com a companhia que opera os radares nas estradas, numa entrevista disse que esses radares "tiram o prazer de guiar". Ele está flexibilizando e institucionalizando ainda mais a impunidade. Veja outros exemplos, ele pretende que uma pessoa não perca a carta com 25 pontos, quer que seja com 40 pontos; ou o seu objetivo de flexibilizar o uso das cadeirinhas para as crianças nos carros. Eu fico pensando, "será que isso é de direita? Será que os militares querem isso?" - imaginando que os militares sejam de direita. Eu não gostaria de estar associando isso como sendo de direita, mas sim como uma pessoa extremamente egoísta e sem visão estadista. Um estadista tem que proteger a população e não pode ser o que ele está sendo, que é uma pessoa extremamente arrogante, inexperiente e, na minha opinião, burra. Há estudos que dizem que se você fizer tal coisa de acordo com os números, acontece outra, mas ele nega os estudos. Desculpe, eu não sou de direita, mas se fosse me sentiria muito ofendida, se fosse associada a este tipo de coisas cretinas a ser de direita. Agora falando de democracia: este presidente é totalmente antidemocrático. O nosso prefeito anterior, Haddad, é extremamente democrático, e fez acontecer as estruturas cicloviárias com muito debate. A direita não viu isto porque não queria ver. Eu não acho que Haddad seja de esquerda. Ele é um humanista.

\section{Acho que é tudo. Não sei se gostaria de acrescentar mais alguma coisa...}

Eu só imagino que essa onda mais reacionária do mundo atual é contra a ocupação dos espaços públicos. Porque os espaços públicos não ocupados facilitam as ditaduras. Eu me lembro quando era criança e vivia na ditadura brasileira, 4 ou 5 pessoas eram dispersadas por policiais nas ruas porque era muita gente conversando para eles. O direito de ir e vir não pode acabar dessa maneira só porque a direita não quer gente ocupando o espaço público.

\section{Notas:}

1 Link para o site da UAF: https://uafestival.wordpress.com/uaf/

2 Link para o site: https:/ / bikeelegal.com/

3 Presidente do Brasil de 1995 a 2002. 
4 Link para o documentário: https:/ / www.youtube.com/watch?v=MRadb3_guDk \&t=172s

$5 \quad$ Prefeito da cidade de São Paulo entre 1997 e 2001.

6 Nota dos autores: A sigla significa Bicycle MotoCross e serve para designar o desporto com bicicleta realizado sobre pistas de terra.

7 Link para o Ciclocidades: https://www.ciclocidade.org.br/

8 Link para o CicloBR: http://ciclobr.org.br/home

9 Link para notícia: https://www.dn.pt/sociedade/da-pasteleira-a-bmx-uma-cidade-onde-as-bicicletas-tem-prioridade-5499900.html

10 Link para o filme: https://www.youtube.com/watch? $\mathrm{v}=\mathrm{e}$ /BqJUpBgFY\&t=638s

11 Link para Ascobike: http://www.ascobike.org.br/

12 Nota dos autores: Prática de colocar a bicicleta na vertical, com uma roda só, sem por os pés no chão.

13 Nota dos autores: Travões de bicicletas mais caros nos mercados habituais.

14 João Dória é atualmente governador do estado de São Paulo, anteriormente a este cargo, era prefeito do município de São Paulo (2017-2018), abandonou o cargo, ainda antes do término, para se candidatar a governador do estado paulista.

15 Este slogan era representado pelo gesto com dedos da mão em forma de "V" na horizontal.

16 Ex-prefeito do município de São Paulo (2013-2017) e candidato a presidente do Brasil no ano de 2018.

Data de submissão: 25/07/2019 | Data de aceitação: 15/07/2020 